Tohoku J. Exp. Med., 2004, 204, 179-187

\title{
The Effect of Fasting Month of Ramadan on the Abdominal Fat Distribution: Assessment by Computed Tomography
}

\author{
Aylin Yucel, Bumin Degirmenci, Murat Acar, Ramazan Albayrak and Alpay \\ HAKTANIR \\ Department of Radiology, Afyon Kocatepe University School of Medicine, \\ Afyon, Turkey
}

Yucel, A., Degirmenci, B., Acar, M., Albayrak, R. and Haktanir, A. The Effect of Fasting Month of Ramadan on the Abdominal Fat Distribution: Assessment by Computed Tomography. Tohoku J. Exp. Med., 2004, 204 (3), 179-187 — The aim of this study was to evaluate the changes in abdominal fat distribution in the fasting month of Ramadan. Thirty-eight healthy volunteers (17 women and 21 men) who fasted in the month of Ramadan in 2002 were included in this prospective study. Waist, hip and thigh circumferences, weight and height of all subjects were measured. Waist-to-hip ratio (WHR), waist-to-thigh ratio (WTR) and body mass index (BMI) were calculated for each subject. For assessing the fat distribution in the abdomen, computed tomography (CT) was performed. Both subcutaneous and visceral fat areas were calculated by the CT scanning technique. All of the calculations were done before (first measurement) and after (second measurement) Ramadan fasting and the changes were evaluated. No statistically significant differences were found in all subjects between the first and second measurements, which include total, subcutaneous and visceral fat areas, waist, hip and thigh circumferences, weight, BMI, WHR, and WTR $(p>0.05)$. In females and the individuals in their twenties, there was a significant decrease in visceral fat area $(p<0.05)$. Despite of the general opinion that supposes the change of weight during the fasting month of Ramadan, there were no significant differences in weight and abdominal fat distribution. However in female and young individuals, there was a reduction in visceral fat compartment. This could be due to fat redistribution, because they have more physical activity than males and older individuals. — computed tomography; fat; abdomen

(C) 2004 Tohoku University Medical Press

Received July 9, 2004; revision accepted for publication August 31, 2004.

Address for reprints: Aylin Yucel, M.D., Department of Radiology, Afyon Kocatepe University School of Medicine, 03200, Afyon, Turkey.

e-mail: aylin_y@yahoo.com

This paper has been presented at the $89^{\text {th }}$ Scientific Assembly and Annual Meeting of the RSNA 2003 in Chicago, IL, USA. 
Millions of Muslims all over the world are used to fast during the month of Ramadan, the ninth month of the Islamic calendar of Hijra (Hallak and Nomani 1988). During the fasting month of Ramadan, Muslims abstain themselves from food and drink from sunrise until sunset (Husain et al. 1987; Hallak and Nomani 1988; Finch et al. 1998; Sweileh et al. 1992). The effect of Ramadan fasting on body weight and composition remains a controversial issue. In general, a reduction in body weight was reported during Ramadan fasting (Husain et al. 1987; Hallak and Nomani 1988; Sweileh et al. 1992; Ramadan et al. 1999), but some groups may gain weight during this month (Frost and Pirani 1987; Hallak and Nomani 1988). No significant changes in body weight and body composition were also reported (El Ati et al. 1995; Finch et al. 1998; Ramadan 2002).

It is known that distribution of abdominal fat is related to metabolic disorders (glucose intolerance and hyperlipidemia), hypertension and ischemic heart disease (Fujioka et al. 1987; Stallone et al. 1991; Kooy and Seidell 1993; Suzuki et al. 1993; Keller et al. 1999; Yoshizumi et al. 1999; Kobayashi et al. 2002). Intraabdominal visceral fat accumulation is a better predictor of total cardiovascular morbidity and mortality rather than subcutaneous fat depot (Stallone et al. 1991; Kooy and Seidell 1993; Suzuki et al. 1993; Yoshizumi et al. 1999).

The documentation of fat distribution in various disease states depended in the past on anthropometric measurements of body circumferences or measurements of skin fold thicknesses (Grauer et al. 1984; Ashwell et al. 1985; Enzi et al. 1986; Kvist et al. 1986; Shuman et al. 1986; Kooy and Seidell 1993; Keller et al. 1999; Yoshizumi et al. 1999). However, abdominal subcutaneous fat thickness is a poor predictor of total abdominal fat because it is unrelated to the amount of intraabdominal fat (Enzi et al. 1986; Shuman et al. 1986; Kooy and Seidell 1993).

Computed tomography (CT) has both highcontrast resolution and cross-sectional imaging capability which makes possible the accurate quantification of subcutaneous fat, of previously immeasurable fat in the internal body compartments (Grauer et al. 1984; Ashwell et al. 1985; Shuman et al. 1986; Seidell et al. 1990; Stallone et al. 1991; Kooy and Seidell 1993; Lemieux et al. 1999; Yoshizumi et al. 1999). CT is the "gold standard" technique for the accurate assessment of intra-abdominal fat (Keller et al. 1999; Yoshizumi et al. 1999).

The purpose of this prospective CT study was to evaluate the changes of abdominal fat distribution during the Ramadan fasting. To our knowledge, this article is the first to show Ramadan fasting effects on the abdominal fat distribution using a radiological technique.

\section{Materials ANd Methods}

All the measurements in this study were performed just before the month of Ramadan, represented by the first measurement and after, represented by the second measurement. Informed consent was obtained from all volunteers, and the protocol of investigation was approved by the ethical committee of our institution.

\section{Patient population}

Thirty-eight healthy volunteers (17 women, $44.7 \%$ and 21 men, $55.3 \%$ ) with an age range of 20-45 years (in twenties 8 men and 11 women, in thirties 7 men and 3 women, and in forties 6 men and 3 women; mean age, $32.5 \pm 12.5$ years) who fasted during the month of Ramadan were included in this study.

This investigation was performed in the Ramadan month that was between November 5th and December 4th in 2002. Because Hijra is a lunar calendar, Ramadan moves back by 11 days in the Gregorian calendar every year. The first, predawn meal called as "Sahur" was offered at about 4:00 a.m. The second meal, a kind of combination of lunch and dinner called as 'Iftar' was served at sunset at about 5:00 p.m. Volunteers eat and drink nothing between these two meals.

There were some limitations in this study. 
Food intake and activity before and during Ramadan fasting were not recorded, because of lack of cooperation. But, it was known that all volunteers had similiar physical activity and eating habitus.

\section{Anthropometric measurements}

In standing position, waist, hip and thigh circumferences of all volunteers were obtained with a non-stretchable tape measure. The waist circumference was measured at the narrowest circumference. Vice versa, the hip circumference was measured at the widest circumference. The thigh girth was measured at the midpoint between the inguinal crease and the patella. The waist-tohip ratio (WHR) was calculated by dividing the waist measurement by the hip measurement. The waist-to-thigh ratio (WTR) was calculated by dividing the waist circumference by the hip circumference. Body weight and standing height were also measured using a balance scale with subjects wearing hospital gowns without shoes. Body mass index (BMI) was calculated by dividing the weight in $\mathrm{kg}$ to height in $\mathrm{m}^{2}$.

\section{CT protocol}

CT (Toshiba Express TSX-011A; Toshiba, Tokyo) was performed with all subjects supine with both arms stretched above the head $(120 \mathrm{kV}$, $50 \mathrm{~mA}$, slice thickness of $10 \mathrm{~mm}$, scanning time of 1 second, field of view of $400 \mathrm{~mm}$, display matrix of $512 \times 512$ pixels). Two regions of interest (ROI) were used. First ROI was used to designate the total fat area margins near the body surface. The trackball-controlled cursor was used as a drawing tool in the area that outlined ROI by tracing the skin. Second ROI was used to designate the visceral fat area. Using the cursor, a line was drawn within the muscle wall surrounding the abdominal cavity. The abdominal subcutaneous fat area was calculated by subtracting the visceral fat area from the total abdominal fat area. The intraabdominal visceral and subcutaneous fat areas were determined at the level of umbilicus (approximately at the level of L4 and L5) similar to the previously reported CT scanning technique (Dixon 1983; Ashwell et al. 1985; Kvist et al. 1986; Shuman et al. 1986; Kooy and Seidell 1993; Keller et al. 1999; Lemieux et al. 1999; Yoshizumi et al. 1999; Kobayashi et al. 2002). As the ROI for intra-abdominal fat passes through

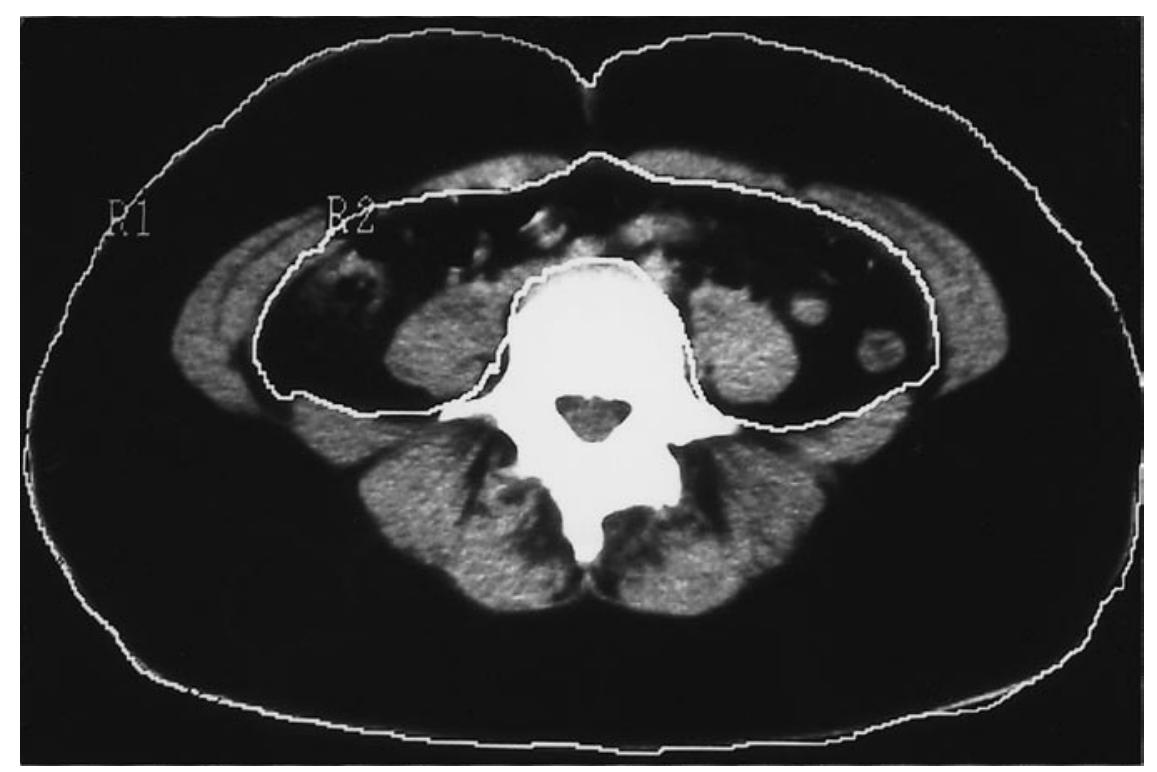

Fig. 1. CT image of a patient at the level of umbilicus. The regions of interest were shown by R1 and R2. R1 was used to assess total cross-sectional area. R2 was used to assess visceral fat. 
rectus abdominis, internal oblique and quadratus lumborum muscles excluding vertebral corpus, the intra-abdominal fat measurement includes retroperitoneal, mesenteric and omental fat (Fig. 1).

In our study, we should have taken axial CT cuts at multiple levels to achieve volumetric calculations with our equipment. However, in order to keep the radiation dose minimum, we took single cross-section. On this single cross section, we made area instead of volumetric calculation. As a matter of fact, the recent studies have already shown that visceral fat area from a single scan obtained at the level of umbilicus was found to be highly correlated with visceral fat volume (Kvist et al. 1986; Kooy and Seidell 1993; Yoshizumi et al. 1999; Kobayashi et al. 2002). Intra-abdominal subcutaneous fat volume also showed a positive correlation with subcutaneous fat area for both genders (Kobayashi et al. 2002).

A CT technician and a dietician performed fat area measurements and all anthropometric measurements, respectively.

\section{Statistical analysis}

Statistical analysis was done using a SPSS version 10.0 statistical programme. Pearson correlation test and $t$-test were used for all parameters. Comparison of each feature in the male and female groups, and three different decades of ages were made by Wilcoxon's ranking test. All results are expressed as mean \pm S.D. A difference with a $p$ value $<0.05$ was considered to be statistically significant.

\section{Results}

First and second measurements of total, subcutaneous and visceral fat tissue areas, weight, waist, hip and thigh circumferences, BMI, WHR, and WTR of all volunteers are listed in Table 1. We found no significant difference in these parameters with Ramadan fasting $(p>0.05)$. Although statistically insignificant, in the second visceral fat tissue area measurement, only one parameter showed a prominent decrease $(p=0.054)$. Both subcutaneous and visceral fat tissue areas showed positively highest correlation between the first and second measurements (subcutaneous fat; $r=0.970, p=0.000$ and visceral fat; $r=0.937, p$ $=0.000)$. The relationship between visceral and subcutaneous fat tissue areas was positively highly correlated in both measurements (first measurement; $r=0.450, p=0.005$ and second measurement; $r=0.564, p=0.000$ ). We also found that subcutaneous fat mass correlated with BMI more strongly than visceral fat mass similar to a previously reported study (subcutaneous fat mass,

TABLE 1. First and second measurements of each parameter of all volunteers

\begin{tabular}{lcccc}
\hline Parameters & $\begin{array}{c}\text { No. of Patients } \\
(n)\end{array}$ & $\begin{array}{c}\text { 1st Measurement } \\
\text { mean } \pm \text { S.D. }\end{array}$ & $\begin{array}{c}\text { 2nd Measurement } \\
\text { mean } \pm \text { S.D. }\end{array}$ & $p$ value \\
\hline Fat area $\left(\mathrm{cm}^{2}\right)$ & & & \\
$\quad$ Total & 38 & $493.09 \pm 144.66$ & $486.42 \pm 159.37$ & 0.242 \\
$\quad$ Subcutaneous & 38 & $330.99 \pm 109.36$ & $331.46 \pm 118.25$ & 0.922 \\
$\quad$ Visceral & 38 & $162.10 \pm 57.52$ & $155.36 \pm 59.29$ & 0.054 \\
Weight & 34 & $68.67 \pm 14.43$ & $68.64 \pm 14.66$ & 0.894 \\
Waist circumference & 34 & $83.29 \pm 13.21$ & $83.44 \pm 12.82$ & 0.822 \\
Hip circumference & 34 & $99.94 \pm 7.87$ & $99.75 \pm 7.38$ & 0.669 \\
Thigh circumference & 34 & $54.66 \pm 4.16$ & $56.25 \pm 8.04$ & 0.198 \\
BMI & 34 & $24.63 \pm 4.39$ & $24.60 \pm 4.36$ & 0.764 \\
WHR & 34 & $0.83 \pm 0.00$ & $0.83 \pm 0.00$ & 0.590 \\
WTR & 34 & $1.52 \pm 0.21$ & $1.49 \pm 0.23$ & 0.275 \\
\hline
\end{tabular}

* Compared by using the paired $t$-test. 
$r=0.930$; visceral fat mass, $r=0.660$ ) (Kobayashi et al. 2002).

In both measurements, age showed positively strong correlation with visceral fat tissue area (first measurement; $r=0.538, p=0.001$ and second measurement; $r=0.592, p=0.000$ ), and moderate correlation with subcutaneous fat tissue area (first measurement; $r=0.401, p=0.014$ and second measurement; $r=0.453, p=0.005)$. When we compared the each parameter in the twenties (age range, 20-29 years; mean age, 25.1 \pm 2.5 years), the thirties (age range, $30-38$ years; mean age, $33.7 \pm 2.5$ years), and the forties (age range, 40-45 years; mean age, $42.3 \pm 2.0$ years), there were significant decrease in visceral fat tissue area in the twenties (first measurement mean \pm S.D.: $138.80 \pm 32.74$ and second measurement mean \pm S.D.: $128.19 \pm 32.39, p=0.014)$, and significant increase in hip circumference in the thirties (first measurement mean \pm S.D.: $100.00 \pm 6.21$ and second measurement mean \pm S.D.: $101.00 \pm$ $6.56, p=0.047)$. We found no significant difference in all parameters of the volunteers at their forties. $P$ values of each parameter in the twenties, thirties and forties were summarized in Table 2.

All the parameters for men and women were shown in Tables 3 and 4, respectively. There was a significant decrease in visceral fat tissue area in women $(p=0.035, p<0.05)$.

\section{DiscuSsion}

Nutritional intake and frequency of meals are changed during Ramadan fasting (Frost and Pirani 1987; Husain et al. 1987; Hallak and Nomani 1988; Sweileh et al. 1992; Ramadan et al. 1999). Although total food consumption is limited during the month of Ramadan, more main dishes are prepared at home, and more desserts are usually consumed than other days. Furthermore, many individuals reduce their physical activity during the month of Ramadan (Hallak and Nomani 1988). As a result, total body metabolism is affected and lipid metabolism and blood lipid levels change during this month (Husain et al. 1987; Hallak and Nomani 1988; Sweileh et al. 1992; El Ati et al. 1995; Adlouni et al. 1998; Ramadan et al. 1999).

Several techniques have been developed to assess abdominal fat tissue. Although anthropometric measurements, such as skin fold thickness or circumferences of different body segments and waist-to-hip circumference ratio are simple and useful indicators of visceral fat accumulation,

TABLE 2. P values ${ }^{*}$ of each parameter in individuals at different ages

\begin{tabular}{lccc}
\hline Parameters & $\begin{array}{c}\text { Twenties } \\
(20-29 \text { years }) \\
(n=19)\end{array}$ & $\begin{array}{c}\text { Thirties } \\
(30-38 \text { years }) \\
(n=10)\end{array}$ & $\begin{array}{c}\text { Forties } \\
(40-45 \text { years }) \\
(n=9)\end{array}$ \\
\hline Fat area $\left(\mathrm{cm}^{2}\right)$ & & & \\
$\quad$ Total & 0.084 & 0.114 & 0.139 \\
$\quad$ Subcutaneous & 0.629 & 0.093 & 0.066 \\
$\quad$ Visceral & $0.014^{*}$ & 0.508 & 0.859 \\
Weight & 1.000 & 0.192 & 0.237 \\
Waist circumference & 0.810 & 0.154 & 0.611 \\
Hip circumference & 0.460 & $0.047^{*}$ & 0.733 \\
Thigh circumference & 0.690 & 0.429 & 0.116 \\
BMI & 0.836 & 0.314 & 0.237 \\
WHR & 0.983 & 0.374 & 0.398 \\
WTR & 0.472 & 0.515 & 0.176 \\
\hline
\end{tabular}

${ }^{*}$ Compared by using the Wilcoxon test. 
A. Yucel et al.

TABLE 3. First and second measurements of each parameter of men

\begin{tabular}{lcccc}
\hline Parameters & $\begin{array}{c}\text { No. of Patients } \\
(n)\end{array}$ & $\begin{array}{c}\text { 1st Measurement } \\
\text { mean } \pm \text { S.D. }\end{array}$ & $\begin{array}{c}\text { 2nd Measurement } \\
\text { mean } \pm \text { S.D. }\end{array}$ & $p$ value $^{*}$ \\
\hline Fat area $\left(\mathrm{cm}^{2}\right)$ & & & & \\
$\quad$ Total & 21 & $511.63 \pm 152.74$ & $507.90 \pm 161.00$ & 0.434 \\
$\quad$ Subcutaneous & 21 & $329.75 \pm 115.48$ & $329.14 \pm 114.47$ & 0.931 \\
$\quad$ Visceral & 21 & $181.88 \pm 56.69$ & $178.76 \pm 62.58$ & 0.394 \\
Weight & 18 & $75.93 \pm 14.97$ & $75.77 \pm 14.94$ & 0.569 \\
Waist circumference & 18 & $89.47 \pm 12.52$ & $89.86 \pm 11.67$ & 0.433 \\
Hip circumference & 18 & $101.57 \pm 7.95$ & $101.41 \pm 7.30$ & 0.639 \\
Thigh circumference & 18 & $54.25 \pm 4.79$ & $54.36 \pm 4.97$ & 0.710 \\
BMI & 18 & $25.16 \pm 4.22$ & $25.03 \pm 4.16$ & 0.642 \\
WHR & 18 & $0.87 \pm 0.00$ & $0.88 \pm 0.00$ & 0.528 \\
WTR & 18 & $1.64 \pm 0.16$ & $1.65 \pm 0.15$ & 0.948 \\
\hline
\end{tabular}

${ }^{*}$ Compared by using the Wilcoxon test.

TABLE 4. First and second measurements of each parameter of women

\begin{tabular}{lcccc}
\hline Parameters & $\begin{array}{c}\text { No. of Patients } \\
(n)\end{array}$ & $\begin{array}{c}\text { 1st Measurement } \\
\text { mean } \pm \text { S.D. }\end{array}$ & $\begin{array}{c}\text { 2nd Measurement } \\
\text { mean } \pm \text { S.D. }\end{array}$ & $p$ value* $^{*}$ \\
\hline Fat area $\left(\mathrm{cm}^{2}\right)$ & & & & \\
$\quad$ Total & 17 & $470.18 \pm 134.98$ & $460.78 \pm 158.22$ & 0.309 \\
$\quad$ Subcutaneous & 17 & $332.52 \pm 104.78$ & $334.32 \pm 126.25$ & 0.943 \\
$\quad$ Visceral & 17 & $137.66 \pm 49.85$ & $126.46 \pm 40.33$ & $0.035^{*}$ \\
Weight & 16 & $62.10 \pm 10.43$ & $60.61 \pm 9.49$ & 0.469 \\
Waist circumference & 16 & $77.35 \pm 11.32$ & $76.21 \pm 10.11$ & 0.736 \\
Hip circumference & 16 & $99.27 \pm 8.79$ & $97.87 \pm 7.24$ & 0.833 \\
Thigh circumference & 16 & $55.47 \pm 3.70$ & $58.37 \pm 10.26$ & 0.082 \\
BMI & 16 & $24.45 \pm 4.70$ & $24.12 \pm 4.67$ & 0.438 \\
WHR & 16 & $0.77 \pm 0.00$ & $0.77 \pm 0.00$ & 0.569 \\
WTR & 16 & $1.39 \pm 0.16$ & $1.32 \pm 0.18$ & 0.352 \\
\hline
\end{tabular}

${ }^{*}$ Compared by using the Wilcoxon test.

these indices are not always accurate (Grauer et al. 1984; Ashwell et al. 1985; Enzi et al. 1986; Kvist et al.1986; Shuman et al. 1986; Kooy and Seidell 1993; Keller et al. 1999; Yoshizumi et al. 1999). CT determination of adipose tissue is the most direct method has made possible the discrimination between adipose tissue located subcutaneous and visceral compartment, an exercise which was not possible with conventional anthropometric techniques (Dixon 1983; Grauer et al. 1984; Ashwell et al. 1985; Enzi et al. 1986; Kvist et al. 1986; Shuman et al. 1986; Seidell et al. 1990; Stallone et al. 1991; Kooy and Seidell 1993; Keller et al. 1999; Lemieux et al. 1999; Yoshizumi et al. 1999; Kobayashi et al. 2002).

The other radiological techniques used to determine the abdominal fat distribution are ultrasonography (US) and magnetic resonance imaging (MRI) (Seidell et al. 1990; Kooy and Seidell 1993; Suzuki et al. 1993; Yoshizumi et al. 1999). US seems to be more appropriate to assess the thickness of subcutaneous fat layers (Kooy and 
Seidell 1993). MRI equipment is more expensive and less available than is CT equipment (Yoshizumi et al. 1999). On the other hand, MRI examination takes longer time to perform (Seidell et al. 1990; Kooy and Seidell 1993). It was also reported that, visceral adipose tissue seemed to be underestimated by MRI compared with CT (Seidell et al. 1990; Kooy and Seidell 1993).

The method of evaluating intraabdominal visceral fat area using CT was reported previously, and this fat was suggested to play an important role in the development of diabetes mellitus, hypertension and hyperlipidemia (Fujioka et al. 1987; Kooy and Seidell 1993; Suzuki et al. 1993; Keller et al. 1999; Yoshizumi et al. 1999; Kobayashi et al. 2002).

We found that there were no significant $(p>$ 0.05 ) changes in the parameters; weight, total, subcutaneous and visceral fat tissue areas, waist, hip and thigh circumferences, BMI, WHR, WTR between the first and second measurements. This was parallel with the results of some studies in which no significant difference in body weight and body composition were observed with Ramadan fasting (El Ati 1995; Finch et al. 1998; Ramadan 2002). It was explained by qualitative and quantitative circadian changes of feeding during Ramadan being counterbalanced by specific metabolic changes in order to preserve normal body weight and composition (El Ati et al. 1995). Other studies showed that total body weight was decreased with the reduction in fluid and energy intake during fasting and in sleeping time (Husain et al. 1987; Hallak and Nomani 1988; Sweileh et al. 1992; Ramadan et al. 1999). Another study, however, revealed an opposite result; the energy intake during Ramadan was significantly higher than at any time of the year. Although there was a significant reduction in meal frequency and the number of meals taken without the family, a significant increase in body weight was noted during Ramadan (Keller et al. 1999).

In this study, not only age and visceral fat tissue area had positively strong correlation between before and after fasting, but also subcutane- ous fat tissue area was moderately correlated with age. As expected, body fat deposition especially in visceral fat compartment is found to be increased as the age increases. In the twenties, although there was no change in weight, we found a decrease in visceral fat tissue after fasting. However, there was no difference in the forties. Age seems to be an important parameter when changes of fat distribution in fasting people are evaluated because it is a factor affected directly by personal activity. Young people are more active and they use up more calories than older people during the day. They also have a higher level of basal metabolism.

There was a statistically significant reduction in visceral fat tissue area in women in our study ( $p$ $<0.05$ ). It was shown that during a short period of reduced energy intake, women lost body weight more from visceral fat compartment than subcutaneous fat (Jones and Edwards 1999). The reduction in visceral fat area was highly correlated with the reduction in total body fat mass and also correlated well with the change in weight and in BMI (Stallone et al. 1991). However, there was no statistical significant weight loss in women in our study. This could be explained by fat redistribution.

It was reported that females experienced a decrease in body mass of greater magnitude than males in Ramadan. This was explained by in accordance with local custom, the onus of meal preparation for breaking fast at about 7:00 p.m. and commencing fast at about 4:00 a.m. being associated with a high level of physical activity involving only the womenfolk (Husain et al. 1987). Housewives, other than cooking, also do the housework like cleaning, ironing, laundry, taking care of children during the whole day at home and working women, besides do the housework, work at the office throughout the whole day, so they use up more energy than men. To our opinion, this increase in physical activity did not lead weight loss, but caused redistribution in visceral fat compartment.

In conclusion, despite of general belief that 
supposed change of weight during Ramadan, we found no significant differences of weight and fat distribution in the abdomen before and after fasting by using CT, the "gold standard" technique for quantifying fat depots. It could be said that Ramadan fasting had no adverse effect and additional new risk of metabolic disorders and cardiovascular disease on the subjects. However, in females and young people, there was a statistically significant reduction in visceral fat compartment. This could be due to fat redistribution, because they have more physical activity than males and older people.

\section{Acknowledgments}

We would like to thank Hülya Ellidokuz, the chief of Public Health Department, for her aid in statistical analysis; Esen Karaca, from Nutrition and Dietetic Department, for her anthropometric measurements of all volunteers, Olcay Ulucan, the technician of CT unit, who dealt with all postprocessing, and also, the volunteers for their excellent collaboration.

\section{References}

Adlouni, A., Ghalim, N., Saile, R., Hda, N., Parra, H.J. \& Benslimane, A. (1998) Beneficial effect on serum apo AI, apo B and Lp AI levels of Ramadan fasting. Clin. Chim. Acta, 271, 179-189.

Ashwell, M., Cole, T.J. \& Dixon, A.K. (1985) Obesity: new insight into the anthropometric classification of fat distribution shown by computed tomography. Br. Med. J., 290, 1692-1694.

Dixon, A.K. (1983) Abdominal fat assessed by computed tomography: Sex difference in distribution. Clin. Radiol., 34, 189-191.

El Ati, J., Beji, C. \& Danguir, J. (1995) Increased fat oxidation during Ramadan fasting in healthy women: an adaptative mechanism for bodyweight maintenance. Am. J. Clin. Nutr., 62, 302-307.

Enzi, G., Gasparo, M., Biondetti, P.R., Fiore, D., Semisa, M. \& Zurlo, F. (1986) Subcutaneous and visceral fat distribution according to sex, age, and overweight, evaluated by computed tomography. Am. J. Clin. Nutr., 44, 739-746.

Finch, G.M., Day, J.E., Razak, Welch, D.A. \& Rogers, P.J. (1998) Appetite changes under free-living conditions during Ramadan fasting. Appetite, $\mathbf{2}$,
159-170.

Frost, G. \& Pirani, S. (1987) Meal frequency and nutritional intake during Ramadan: a pilot study. Hum. Nutr. Appl. Nutr., 41, 47-50.

Fujioka, S., Matsuzawa, Y., Tokunaga, K. \& Tauri, S. (1987) Contribution of intra-abdominal fat accumulation to the impairment of glucose and lipid metabolism in human obesity. Metabolism, 36, 54-59.

Grauer, W.O., Moss, A.A., Cann, C.E. \& Goldberg, H.I. (1984) Quantification of body fat distribution in the abdomen using computed tomography. Am. J. Clin. Nutr., 39, 631-637.

Hallak, M.H. \& Nomani, M.Z.A. (1988) Body weight loss and changes in blood lipid levels in normal men on hypocaloric diets during Ramadan fasting. Am. J. Clin. Nutr., 48, 1197-1210.

Husain, R., Duncan, M.T., Cheah, S.H. \& Ch'ng, S.L. (1987) Effects of fasting in Ramadan on Tropical Asiatic Moslems. Br. J. Nutr., 58, 41-48.

Jones, P.R. \& Edwards, D.A. (1999) Areas of fat loss in overweight young females following an 8-week period of energy intake reduction. Ann. Hum. Biol., 26, 152-162.

Keller, C., Chintapalli, K. \& Lancaster, J. (1999) Correlation of Anthropometry with CT in MexicanAmerican women. Res. Nurs. Health, 22, 145-153.

Kobayashi, J., Tadokoro, N., Watanabe, M. \& Shinomiya, M. (2002) A novel method of measuring intra-abdominal fat volume using helical computed tomography. Int. J. Obesity, 26, 398-402.

Kooy, K.V.D. \& Seidell, J.C. (1993) Techniques for the measurement of visceral fat: a practical guide. Int. J. Obesity, 17, 187-196.

Kvist, H., Sjöström, L. \& Tylén, U. (1986) Adipose tissue volume determinations in women by computed tomography: Technical considerations. Int. J. Obesity, 10, 53-67.

Lemieux, S., Lesage, M., Bergeron, J., Prud'homme, D. \& Despres, J.P. (1999) Comparison of two techniques for measurement of visceral adipose tissue cross-sectional areas by computed tomography. Am. J. Hum. Biol., 11, 61-68.

Ramadan, J. (2002) Does fasting during Ramadan alter body composition, blood constituents and physical performance? Med. Princ. Pract., 2, 41-46.

Ramadan, J., Telahoun, G., Al-Zaid, N.S. \& BaracNieto, M. (1999) Responses to exercise, fluid, and energy balances during Ramadan in seden- 
tary and active males. Nutrition, 15, 735-739.

Seidell, J.C., Bakker, C.J.G. \& Kooy, K.V.D. (1990) Imaging techniques for measuring adipose-tissue distribution-a comparison between computed tomography and 1.5-T magnetic resonance. Am. J. Clin. Nutr., 51, 953-957.

Stallone, D.D., Stunkard, A.J., Wadden, T.A., Foster, G.D., Boorstein, J. \& Arger, P. (1991) Weight loss and body fat distribution: a feasibility study using computed tomography. Int. J. Obesity, 15, 775-780.

Shuman, W.P., Morris, L.L.N., Leonetti, D.L., Wahl, P.W., Moceri, V.M., Moss, A.A. \& Fujimoto, W.Y. (1986) Abnormal body fat distribution detected by computed tomography in diabetic men. Invest. Radiol., 21, 483-487.

Suzuki, R., Watanabe, S., Hirai, Y., Akiyama, K., Nishide, T., Matsushima, Y., Murayama, H.,
Ohshima, H., Shinomiya, M., Shirai, K., Saito, Y., Yoshida, S., Saisho, H. \& Ohto, M. (1993) Abdominal wall fat index, estimated by ultrasonography, for assessment of the ratio of visceral fat to subcutaneous fat in the abdomen. Am. $J$. Med., 95, 309-314.

Sweileh, N., Schnitzler, A., Hunter, G.R. \& Davis, B. (1992) Body composition and energy metabolism in resting and exercising Muslims during Ramadan fast. J. Sports Med. Phys. Fitness, 32, 156-163.

Yoshizumi, T., Nakamura, T., Yamane, M., Islam, A.H.M.W., Menju, M., Yamasaki, K., Arai, T., Kotani, K., Funahashi, T., Yamashita, S. \& Matsuzawa, Y. (1999) Abdominal fat: Standardized technique for measurement at CT1. Radiology, 211, 283-286. 